\title{
Change of microstructure and properties of dual titanium alloy join interface in hot working history
}

YAO Zekun, NING Yongquan, ZHAO Zhanglong, HUANG Darong, GUO Hongzhen School of materials and engineering, Northwestern Polytechnic University, Xi'an, China, 710072

\begin{abstract}
In order to get workpiece with high tensile stresses in bore region and high temperature duration, creep strength in outskirts, the dual alloy samples made of high temperature titanium alloy Ti60 and high strength titanium alloy Ti6246 had been joined by inertia friction welding(IFW). Then these samples were isothermal forged at 9400c and 9750c, and different heat treatment followed. Changes of microstructure and properties of dual titanium alloy join interface in hot working history were examined at this article. The results show equiaxed $\alpha$ structure varied into basketweave structureat at as-welded join interface, especially a character of widmannstaten structure emerged from Ti6246 alloy side heat effect region, after gradient heat treatment. Immersed ultrasonic testing prove deformation can availably eliminate weld defect through metal on two side of weld line deeper embedding each other. The results of properties test also show the join strength of dual titanium alloy through isothermal deformation and gradient heat treatment are better than that of as-welded samples. Tensile strength, yield strength, elongating rate, reduction in area of sample at $5500 \mathrm{c}$ also increase 51 to $145 \mathrm{MPa}, 37$ to $101 \mathrm{MPa}, 1.6 \%$ to $5.3 \%, 15.3 \%$ to $3.3 \%$ than that of as-welded samples respectively. The rupture life of Ti60/Ti6246 dual titanium samples with join interface can sustain to go beyond 100 hours at 5500c and 320 PMa stress.
\end{abstract}

Key words: Ti60/Ti6246 dual titanium alloy; isothermal deformation; gradient heat treatment; microstructure; property

\section{Introduction}

Compressor disk and impeller in aero-engine have endured a great temperature and stress gradient during operation. In order to increase ratio of thrust and weight or power and weight, more harsh operating conditions of high temperature and pressure that are now frequently projected place increased demands on engine components and materials [1-2]. Therefore, the temperature and stress gradient will be greater for Compressor disk and impeller. Temperature of their rim will exceed or near $600^{\circ} \mathrm{C}$, the compressor disc or impeller made of monolithic titanium alloy does not achieve this temperature. Therefore, a dual alloy disk or impeller will be necessary for to exceed 6000 c capability[2].

At present, those alloys, such as Ti3Al, Ti2AlNb, and high temperature titanium alloy Ti60, IMI834 etc., have hope to be used as high temperature region of dual alloy compressor disk or impeller because of excellent elevated temperature properties and oxidation resistance. These alloys can withstand temperature $6000 \mathrm{c}$ or over $6000 \mathrm{c}$ [3-5]. The familiar high intensity titanium alloys, such as Ti-6246, Ti-17 and Ti-1023, have intensity exceed $1000 \mathrm{MPa}$ at room temperature, So they can use as core region of dual alloy compressor disk or impeller.

For dissimilar alloy, good join strength depend their compatibility of composition, modulus of elasticity and thermal expansion coefficient. The closer their compatibility is, the fewer flaw is, the higher join strength is. They can be welded by electron beam welding (EBW) or inertia friction weld (IFW), but after EBW process, the microstructures of weld were solidification crystals with coarse columnar grains and equiaxed grains [6].

Inertia friction welding technique is a good method to obtain high join strength. It has not only narrow welding line, but also get appropriate microstructures at weld zone through post-treat or isothermal deformation plus post-treat. In investigating IFW of Dissimilar nickel-based Superalloys, Mar-M247 investment-cast and LSHR isothermally forged powder metallurgy, OLEG N. SENKOV, DAVID W. MAHAFFEY, et al. found abrupt boundaries are present between this fine-grained layer and coarse grains inside the Mar-M247 alloy, as well as between this fine-grained layer and the grain structure of the LSHR alloy. Small and rounded dark oxide particles and pores, as well as fine, white-color carbide particles are evident near the weld interface[7]. BSE image of the IFW interface region show transition from flat to wavy interface appearance. A radially oriented chain of fine nanometer-sized carbide and oxide particles is seen in the middle of weld interface. The chain of the oxide/carbide particles remains linear, separates from the weld line, and is located inside the Mar-M247 alloy in this region. An increase in the preheat temperature enhanced the plastic flow of Mar-M247 during IFW, which resulted in extensive mechanical mixing with LSHR at the weld interface, the formation of extensive flash on both the Mar-M247 and LSHR sides, and achieved a sound bond[8]. Failures also were seen in the plasticized layer on the aluminum side of the joint for dissimilar friction welding of 6061-T6 aluminum and AISI 1018 steel. The bond lines were characterized by a thin layer of formed Al-Fe intermetallic. This intermetallic layer averaged roughly $250 \mathrm{~nm}$ thick and compositionally appears related to the $\mathrm{FeAl}$ and $\mathrm{Fe} 2 \mathrm{Al} 5$ phases[9]. However, hot working, especially isothermal forging or near isothermal forging, could improve the microstructure of weld zone and enhance the property of weld zone [10]. In this work, it is reported the change of microstructure and properties of the welded dissimilar titanium alloy in hot working history.

\section{Experimental Procedures}

Materials 
Ti60 alloy and Ti6246 alloy are used in this work. Composition of diameter $250 \mathrm{~mm}$ Ti60 provided by Baoji Titanium Industry Co.Ltd is $5.5 \mathrm{Al}-3.7 \mathrm{Sn}-3.1 \mathrm{Zr}-0.88 \mathrm{Mo}-0.40 \mathrm{Nb}-0.35 \mathrm{Si}-0.98 \mathrm{Ta}$, Ti base (wt\%). Composition of diameter $150 \mathrm{~mm} \mathrm{Ti} 6246$ provided by Westerm Superconducting Technologies Co.Ltd is 6.02Al-2.01Sn-4.06Zr- 6.07Mo,Ti base (wt\%). The fore-weld microstructures of two alloys are shown in Fig.1. The parent Ti60 alloy presents typical bimodal microstructure, thereinto, average grain size of equiaxed $\alpha$ phase is about 20 30 $\mu \mathrm{m}$ (Fig. 1(a)). The microstructure of Ti6246 alloy is composed of strip $\alpha$ with aspect ratios about 5 10 (Fig. 1(b)).

Experimental procedures
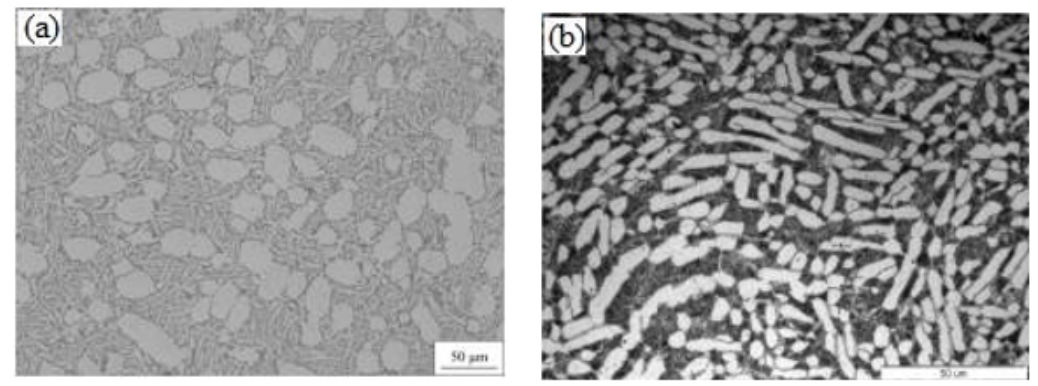

Fig.1 Microstructures of fore-weld alloys: (a) Ti60 (b) Ti6246

Samples were machined into ring billet $(\varnothing 120 \mathrm{~mm} \times \varnothing 56 \mathrm{~mm} \times 60 \mathrm{~mm})$ for Ti60 and shaft billet $(\varnothing 73.6 \mathrm{~mm} \times 76 \mathrm{~mm})$ for TC6246 with 11 degree taper (Fig.2) respectively. The welded surfaces were cleaned before join together. IFW was performed at model 150B inertia friction welder. Weld process is divided into two stages. some parameters were used as follows: $550 \mathrm{r} / \mathrm{min}$ turn rate, $2 \mathrm{MPa}$ pressure, $84.25 \mathrm{~kg}-\mathrm{m} 2$ moment of inertia, 20s hold time at first stage, $1000 \mathrm{r} / \mathrm{min}$ turn rate, $9 \mathrm{MPa}$ pressure, $250.86 \mathrm{~kg}-\mathrm{m} 2$, $20 \mathrm{~s}$ hold time at second stage. Then these samples were isothermal forged at $9400 \mathrm{c}$ and $9750 \mathrm{c}$, and different heat treatment followed. The specification of gradient heat treatment was as follows: outskirt ring Ti60 alloy was solution at 10000c, and bore portion Ti6246 alloy was solution at 9200c for 1 hour, AC, next outskirt ring Ti60 alloy was aged for 2 hours at $7500 \mathrm{c}$ and bore portion Ti6246 alloy was aged for 8 hours at 5930c in gradient heat treatment furnace(see Fig.3).
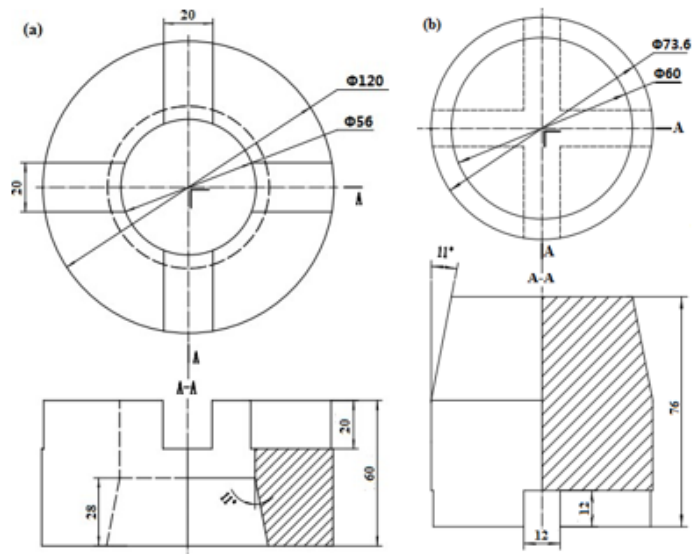

Fig.2 Ring and shaft billet after machining :(a)Ti60 alloy, (b)Ti6246 alloy 


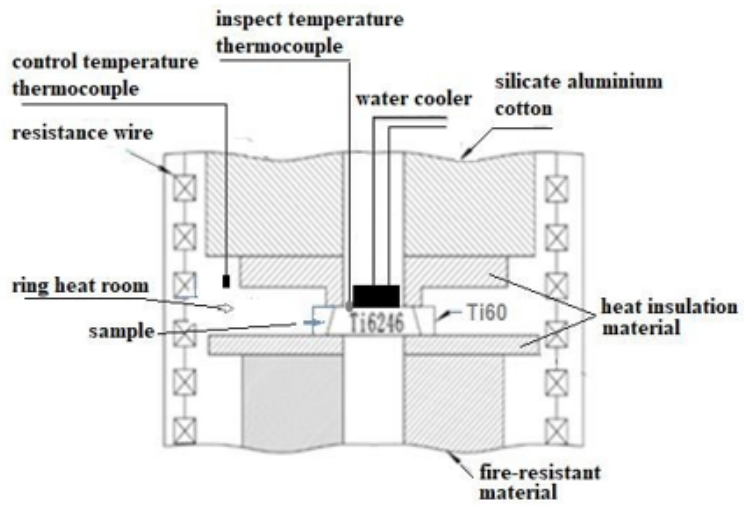

Fig.3 Schematic view of gradient heat treatment furnace

The microstructure was observed on an OLYMPUSPM-G3 microscope. Immersed ultrasonic testing are performed at UST400XL and LS-200LP respectively. Parameters used as follows: $\Phi 0.8 \mathrm{~mm}$ plane bottom hole side, $1 \mathrm{~mm}$ scanning beam interval, 133 and $200 \mathrm{~mm} / \mathrm{s}$ scanning beam velocity, 600 and $900 \mathrm{~Hz}$ repeat frequency, lengthways wave for as-welded and as-forged samples. Tensile tests were carried out at room temperature and $550^{\circ} \mathrm{C}$. Rupture tests were carried out at $5500 \mathrm{c}$, $6000 \mathrm{c}$ and $320 \mathrm{MPa}$ stress. The weld line laid the middle of score on all test samples.

\section{Test results and discuss}

Microstructure of as-welded Ti60 alloy and Ti6246 alloy join interface shows in figure 4. It can be seen Ti60 alloy and Ti6246 alloy table each other. Reason come into being light and dark strip attribute to shaft billet with taper contact ring billet with taper gradually. On hot affect zone(HAZ) of Ti60 alloy side long thick strip $\alpha$ phase grain present in this zone, but microstructure made of few equiaxed and fine strip $\alpha$ phase particles occurred $\beta$ grains on Ti6246 alloy side, and $\beta$ grain boundaries loom. This show temperature was over $\beta$ transus temperature of Ti6246 alloy and greater twisting deformation happen during friction welding.

Immersed ultrasonic detect image of as-welded sample show in Figure 5. It can be seen that there is obviously reflect signal in about 1800 area along circle direction at small taper side, it is about $6 \mathrm{~mm}$ at thickness direction. The cause resulted in this defect is due to depth of axis billet with taper entering taper hole of ring billet is not enough and concentric.
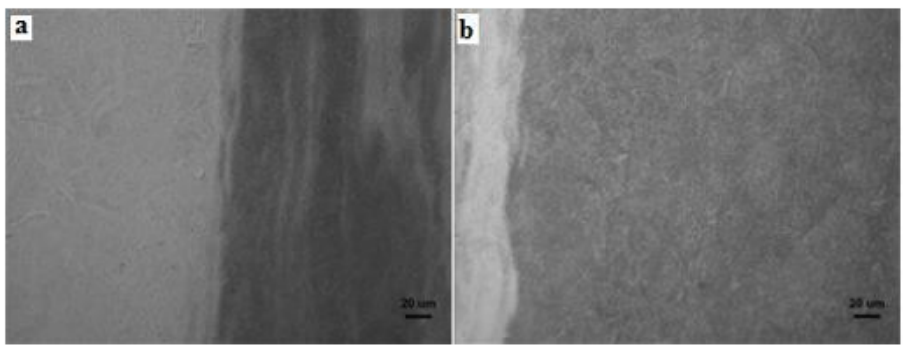

Fig.4 Microstructure of as-welded Ti-60/Ti-6246 join interface: (a) Weld and HAZ of Ti60 alloy side, (b) weld and HAZ of Ti6246 alloy side 


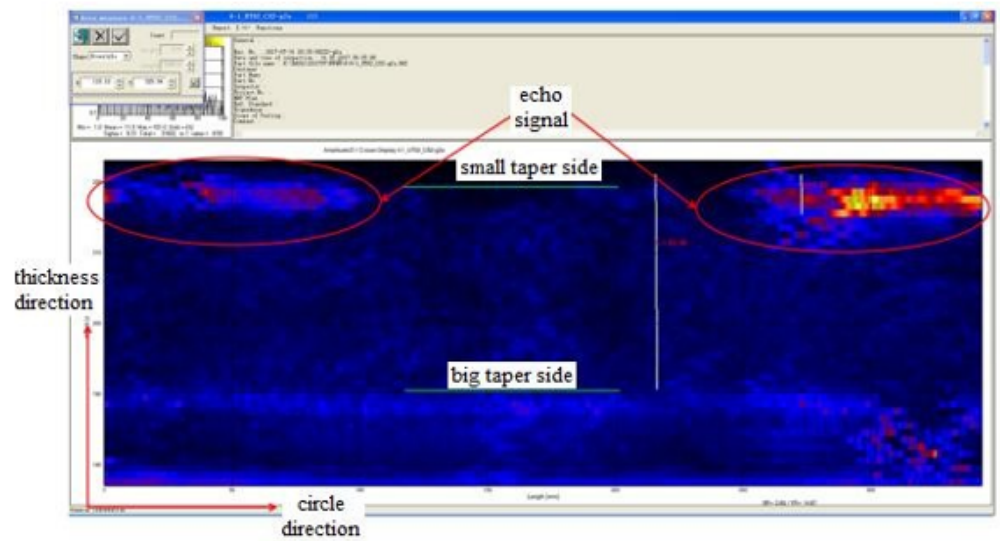

Fig.5 image of immersed ultrasonic detect for as-welded sample

Microstructure of Ti-60/Ti-6246 join interface via isothermal deformation at 9400c and solution treatment at 9200c shows in figure 6. Here, microstructure of Ti6246 alloy side anear weld line is made of short bar and strip $\alpha$ phase, the amount of $\alpha$ phase also is few than as-welded sample. This can be associated with temperature over phase transus temperature of Ti6246 alloy during friction weld and deformation at higher temperature. On HAZ of Ti60 alloy side long strip $\alpha$ may be carry-over during friction weld. Because deformation amount being small $\alpha$ grains only are elongated and are not broken, and at low solution treatment temperature dynamic of recrystallization is no enough. Otherwise, it can be seen from Ti6246 alloy side to Ti60 alloy side transition of microstructure is even and trace of weld also has disappeared.
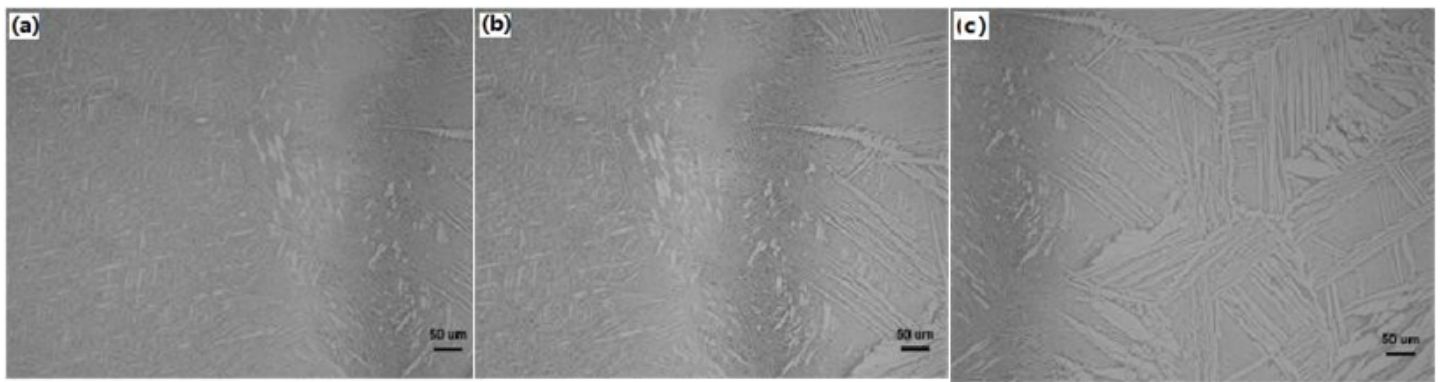

Fig.6 Microstructure of Ti-60/Ti-6246 join interface isothermal deformed at 9400c and 9200c solution treated : (a) HAZ of Ti6246 alloy side, (b) weld line, (c) HAZ of Ti60 alloy side

Immersed ultrasonic detect image of as-welded sample show in Figure 7. It can be seen that no $\geq \varphi 0.8 \mathrm{~mm}$ plane bottom hole equivalent plane bottom hole reflect wave height display are detected in as-forged samples via isothermal forge. It attest to deformation can availably eliminate weld defect through metal on two side of weld deeper embedding each other. 


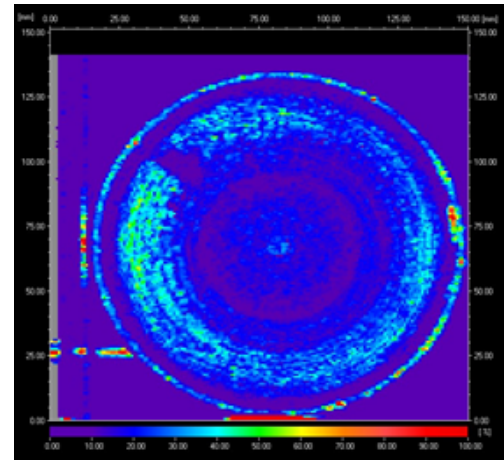

Fig.7 image of immersed ultrasonic detect for as-forged sample

Room temperature and 5500c tensile test values of as-welded samples are given in table 1 display slightly low elongation than Ti60 alloy original material criterion ( about $6 \%$ ). However, the values of UTS at room temperature and 550oC were same level as Ti60 alloy parent metal. Such findings prove that the Ti6246 alloy and weld region was much stronger than Ti60 alloy for room temperature tension test.

Table1: The property of as-welded dual titanium alloy

\begin{tabular}{|c|c|c|c|c|c|}
\hline Test temperature & $\sigma / \mathrm{MPa}$ & $\sigma_{0.2} / \mathrm{MPa}$ & $\delta / \%$ & $\psi / \%$ & Fracture location \\
\hline Room temperature & $1020 / 1010$ & $977 / 966$ & $4.5 / 4.5$ & $17 / 14$ & Ti-60 side \\
\hline $550^{\circ} \mathrm{C}$ & 629 & 549 & 6.5 & 22 & Ti-60 side \\
\hline
\end{tabular}

Microstructure of Ti60/Ti6246 dual titanium alloy join interface after isothermal deformation at 9750c and gradient heat treatment show in figure 8. It is found that mistiness grains at join interface and on Ti60 alloy side have transformed into strip $\alpha$ structure with a little equiaxed $\alpha$. On Ti6246 alloy side the microstructure has transformed into basket-weave structure. The chromatism has existed on two side of join interface all the same, it is slightly light on Ti60 alloy side, and it is shade on Ti6246 alloy side. This is correlated with different $\alpha$ content owing to deformation temperature being over and below phase transus temperature for Ti60 and Ti6246 alloy respectively.

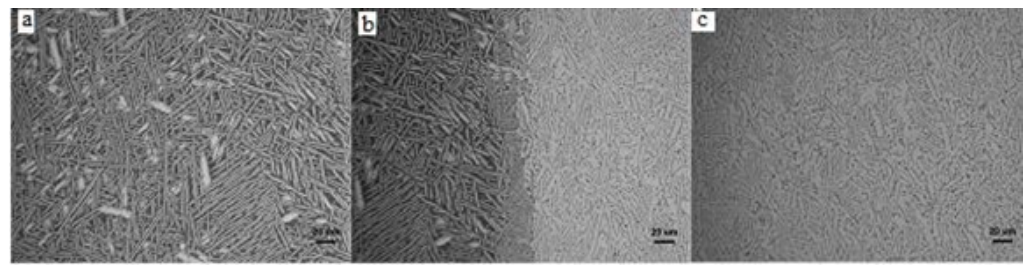

Fig.8 Microstructure of Ti60/Ti6246 join interface after isothermal forging at $9750 \mathrm{c}+$ gradient heat treatment: (a) HAZ on Ti6246 side, (b) interface, (c) HAZ on Ti60 side

Tensile and repture test results of Ti60/Ti6246 dual titanium alloy samples with join interface after isothermal deformation and gradient heat treatment list at table 2 and table 3 respectively. Via isothermal deformation and gradient heat treatment, join 
interface strength of Ti60/Ti6246 dual titanium alloy almost is no change by contrast to as-welded samples. Although elongating rate and reduction in area enhance, extent of data spread around also is greater. Therein,

maximum and minimum of elongating rate is about double. The causation of data spread around is to ascribe uneven microstructure in Ti60 original materials (see figure 9).

Table 2 Tensile properties of Ti-60/Ti6246 join interface after isothermal forging and gradient heat treatment

\begin{tabular}{|c|c|c|c|c|c|c|c|c|}
\hline \multirow{2}{*}{ Sample status } & \multicolumn{4}{|c|}{ Room temperature } & \multicolumn{4}{|c|}{$550^{\circ} \mathrm{C}$} \\
\hline & $\sigma_{b} / \mathrm{MPa}$ & $\sigma_{0.2} / \mathrm{MPa}$ & $87 \%$ & $\psi / \%$ & $\sigma_{b} / M P a$ & $\sigma_{0.2} / \mathrm{MPa}$ & $\delta / \%$ & $\psi / \%$ \\
\hline Isothermal forging at $975^{\circ} \mathrm{c}$ & $1023 / 1181$ & $960 / 1064$ & $4.7 / 11.7$ & $13.1 / 20.3$ & $679 / 869$ & $584 / 716$ & $6.8 / 16.8$ & $25.0 / 66.1$ \\
\hline Isothermal forging at $940^{\circ} \mathrm{C}$ & $1040 / 1170$ & $979 / 1051$ & $6.9 / 12.8$ & $24.6 / 26.0$ & 680 & 586 & 6.1 & 37.3 \\
\hline
\end{tabular}

From table 3 it can be seen rupture life of Ti60/Ti6246 dual titanium samples with join interface can sustain to go beyond 100 hours at 5500c as 320 PMa stress is loaded. Whereas to attain same rupture life at $6000 \mathrm{c}$ and $270 \mathrm{MPa}$ stress only is loaded.

Table 3 Rupture life of dual titanium alloy after isothermal forging and gradient heat treatment

\begin{tabular}{|c|c|c|c|c|}
\hline Sample status & Temperature/ ${ }^{\circ} \mathrm{c}$ & Test stress/MPa & Lasting time/hours & note \\
\hline Ti-60/Ti6246 & 550 & 320 & $>101$ & no rupture \\
Isothermal forging at 975 $\mathrm{c}$ & & & $>101$ & no rupture \\
& 600 & 300 & 54.53 & rupture \\
& & 270 & $>101$ & no rupture \\
\hline
\end{tabular}

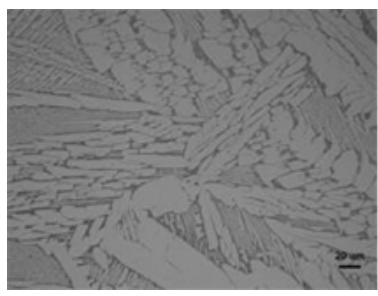

Fig.9 local microstructure in Ti60 original material

\section{Conclusion}

(1) Hot working history can eliminate as-welded trace of Ti60/Ti6246 join interface, transition of microstructure is smoothness, but their form is different on two side of weld due to difference of phase transus temperature.

(2) Deformation can availably eliminate weld defect through metal on two side of weld line deeper embedding each other.

(3) The join strength of Ti60/Ti6246 dual titanium alloy inertia friction welded change no great, but plasticity enhance via isothermal deformation and gradient heat treatment. The rupture life of Ti60/Ti6246 dual titanium samples with join interface can sustain to go beyond 100 hours at 5500c as 320 PMa stress is loaded.

References

[1] James A.Hall, Krish Krishnamurthy, Method of Manufacture of Dual Titanium Alloy Impeller, United States Patent (US 
7841506B2), 2010.

[2] James C. Williams, Materials Requirements for Aircrafft Engines, Aerospace Thermal structures and Materials for a New Era, Edited by Earl A.Thornton, 1995, 359-383.

[3] Christoph Leyens and Manfred Peters. Titanium and Titanium Alloys [M], Wiley-VCH Verlag GmbH \& Co. KgaA, Weinheim, 2003

[4] Jingxia Cao, Fang Bai and Zhenxi Li, Materials Science and Engineering A [J], 2006, 424(1-2): 47

[5] Yonggang Zhang, Yafang Han, Guoliang Chen et al., Structural Intermetallics [M]. Beijing: National Defence Industry Press, 2001: 785.

[6] He Jingshan, Wu Qingsheng, Zhang Binggang et al. Rare Metals [J], 2007, 26(Spec): 242.

[7] OLEG N. SENKOV, DAVID W. MAHAFFEY, S. LEE SEMIATIN, and CHRISTOPHER WOODWARD, Inertia Friction Welding of Dissimilar Superalloys Mar-M247 and LSHR, METALLURGICAL AND MATERIALS TRANSACTIONS A,2014, VOLUME 45A, 2014-5545.

[8] O.N. SENKOV, D.W. MAHAFFEY, and S.L. SEMIATIN, Effect of Preheating on the Inertia Friction Welding of the Dissimilar Superalloys Mar-M247 and LSHR, METALLURGICAL AND MATERIALS TRANSACTIONS A, 2016, VOLUME 47A, 2016-6121.

[9] Emel Taban, Jerry E. Gould, John C. Lippold, Dissimilar friction welding of 6061-T6 aluminum and AISI 1018 steel: Properties and microstructural characterization, Materials and Design 31 (2010) 2305-2311.

[10] L. J. Huang, L. Geng, A. B. Li, X. P. et al. Materials Science and Engineering A [J], 2009, 505(1-2): 136. 